\title{
Rapid indicators for monitoring the health of Chlamydomonas nivalis biomass during preservation
}

\author{
E. Bemejo-Padilla ${ }^{1} \cdot$ H. Kinsou ${ }^{2} \cdot$ R. Filali ${ }^{2} \cdot$ B. Perez-Bibbins ${ }^{2} \cdot$ B. Taidi $^{3}$
}

Received: 1 November 2020 / Revised and accepted: 24 May 2021 / Published online: 2 August 2021

(c) The Author(s) 2021

\begin{abstract}
Microalgae are photosynthetic microorganisms that have increasingly attracted interest in the last decade due to their potential for industrial applications. One crucial aspect for the industrial-scale valorisation of algae biomass concerns the quality control during its preservation before being treated to obtain the end-product. Monitoring biomass quality is essential and can be potentially accomplished with the aid of specific biochemical indicators called biomarkers. In this context, the main aim of this work was to identify potential indicators of microalgae biomass viability that could be used as markers of its quality during storage/preservation for commercial operations. The health status of a suspension of Chlamydomonas nivalis was assessed at $4{ }^{\circ} \mathrm{C}$ and $25^{\circ} \mathrm{C}$ during 10 days of storage. The use of the pulse-amplitude-modulation technique, based on chlorophyll fluorescence, was a valuable indicator of the culture viability. The measurement of DNA and of chlorophyll in the supernatant, indicative of cell lysis, also provided satisfactory results; in the case of the DNA, the limit of detection was $3.9 \mu \mathrm{g}$ DNA $\mathrm{mL}^{-1}$. The effect of different concentrations of a well-known and cheap preservative, acetic acid, was also evaluated at $4{ }^{\circ} \mathrm{C}$. This work identified three suitable biomarkers to be used as rapid indicators of the quality of the microalgal suspension prior to its reception for biorefinery activities.
\end{abstract}

Keywords Microalgae $\cdot$ Biomarkers $\cdot$ Biomass preservation $\cdot$ Chlamydomonas nivalis $\cdot$ Cell viability $\cdot$ DNA $\cdot$ Acetic acid preservative

\section{Introduction}

There is increasing interest in microalgae production due to their capacity to convert carbon dioxide into algal biomass and high-value biomolecules while producing oxygen via

This research work was carried out while Elisabeth Bermejo was working at LGPM, CentraleSupélec, SFR Condorcet FR CNRS 3417, Centre Européen de Biotechnologie Et de Bioéconomie (CEBB), Université Paris-Saclay, 3 rue de Rouges Terres, 51110 Pomacle, France

$\triangle$ R. Filali

rayen.filali@centralesupelec.fr

1 Biochemical and Bioprocess Engineering Group, Department of Chemical Engineering and Analytical Science, The University of Manchester, Manchester, UK

2 LGPM, CentraleSupélec, SFR Condorcet FR CNRS 3417, Centre Européen de Biotechnologie Et de Bioéconomie (CEBB), Université Paris-Saclay, 3 rue de Rouges Terres, 51110 Pomacle, France

3 LGPM, CentraleSupélec, Université Paris-Saclay, 3 rue Joliot-Curie, 91192 Gif-sur-Yvette, France photosynthesis. The ultimate success of an industry based on microalgae culture will depend on a combination of several factors: the choice of suitable strains for each climate, the production logistic to minimise cost, harvesting, transport and biomass treatment (biorefinery) (Chacón-Lee and Gonzàlez-Mariño 2010). Chlamydomonas nivalis is an interesting strain for the production of algal biomass in cold or temperate climates. This psychrophilic microalga has the capacity to bioaccumulate a pigment of interest called astaxanthin. The present study investigated suitable tools for quality control of $C$. nivalis biomass during storage.

Biomass and target product quality control during microalgae preservation/storage represents a big challenge. The preservation of a microalgal culture is a key part of any algae-based industry (Ponis et al. 2008). Quality assurance of the biomass can be potentially accomplished with the aid of analytic quantification of specific biochemical indicators, called biomarkers (Paniagua-Michel and Olmos-Soto 2016). Biomarkers are molecules (or parameters) that can be quantitatively measured and can serve as indicators of changes in specific biological systems following the exposure to different environmental factors (Bermejo et al. 2021). 
Consequently, the importance of finding appropriate biomarkers that can indicate the viability and biomass integrity of microalgae cultures is crucial during transportation and storage. The formation of certain by-products can be used as an indirect way to assess cellular viability, since their measurement can provide relevant information about any drift in the optimal conditions (Veloso and Ferreira 2017). Accordingly, the presence of DNA, by process degradation into oligonucleosomal fragments, can be also used as an indicator of cell death in some species of microalgae (Segovia et al. 2003; Zuppini et al. 2007; Yordanova et al. 2013). Chlorophyll is another molecule that can be used to evaluate the status of a microalgae culture. This pigment, which is an effective indicator of the physiological state of the photosynthetic apparatus, can be easily deactivated and degraded by changes in temperature and $\mathrm{pH}$ since it is very sensitive to these factors (Venkateswaran et al. 2003; Koca et al. 2005). Chlorophyll- $a$ fluorometry measurement, by pulseamplitude-modulation (PAM) technique, has become one of the most common, non-invasive and rapid techniques used to evaluate the physiological status changes and photosynthetic performance efficiency in microalgal cultures (Vonshak et al. 1994; Torzillo et al. 1996 1998; Masojídek et al. 1999 2011; Oxborough et al. 2000; Baker 2008; Kromkamp et al. 2008). The maximum value that can be obtained from this measurement varies between 0.7 and 0.8 in conventional healthy (non-stressed) microalgae cultures (Masojídek et al. 2013). During the preservation of microalgae biomass in the absence of light, this parameter can be a good indicator of PSII status and the potential damage caused by the preservation conditions (e.g. temperature, $\mathrm{pH}$, dissolved oxygen concentration) and/or excess bacterial contamination.

Microalgal biomass is usually dehydrated before being stored, with the associated high cost that treatments such as hot-drying or freeze-drying entail. To make the process more economically feasible, microalgae can be stored in a fresh state which besides has been demonstrated to present certain quality conservation advantages over the concentrated cultures (Verspreet et al. 2020b). Low temperature has been reported to preserve different microalgae species with better viability for longer periods. Additionally, storage in the dark has been described to increase the shelf life of the cultures avoiding oxidative and hydrolytic degradations (Castelló et al. 2017; Verspreet et al. 2020a). In short, storage of microalgae in suspension, in the dark and at lowered temperature may offer a good compromise in terms of preserving the biomass quality and reducing the storage cost for an overall economically viable value chain.

During a classic process of microalgae valorisation with an end-product application in the cosmetic, pharmaceutical or food sectors, one of the major challenges is the preservation of the produced biomass avoiding microbial contamination during storage. Bacterial proliferation may be minimised, by using several additives authorised in the food industry. One of the most common preservatives known to man for thousands of years is acetic acid, a simple carboxylic acid that forms the active compound in vinegar (Dan et al. 2017). Acetic acid can be used to increase the acidity (and lower the $\mathrm{pH}$ ) of food products and is a popular preservative because it limits bacterial growth in dressings, sauces, cheese and pickles. It is used as a natural preservative of food and as an antimicrobial agent not only in vegetable pickling but also as an active component of edible films and in techniques for preservation (Babic 2013).

The present work aimed to evaluate different potential indicators of $C$. nivalis culture viability that could be used in a commercial operation for monitoring its quality postproduction. The biomarkers studied were the maximum photosynthetic efficiency together with the free DNA and chlorophyll presence in the supernatant. As a first approach, C. nivalis was stored (without concentration) in the dark, at $4{ }^{\circ} \mathrm{C}$ and $25^{\circ} \mathrm{C}$ to find the temperature that allowed the optimal fresh biomass preservation. Subsequently, in order to avoid the possible proliferation of bacteria, the addition of acetic acid to the culture was assessed at the temperature with the best results $\left(4^{\circ} \mathrm{C}\right)$. Different concentrations of this preservative were tested so as to find the most favourable for the culture.

\section{Materials and methods}

\section{Microalgal strain culture and storage conditions}

Chlamydomonas nivalis SAG 26.86 was obtained from the Culture Collection of Algae of Göttingen University, Germany-SAG. To prepare the biomass for the preservation study, $C$. nivalis was grown in shake-flask cultures under standard growth conditions $\left(25^{\circ} \mathrm{C} ; \mathrm{CO}_{2}\right.$ enriched to $1 \% \mathrm{v} / \mathrm{v}$; incident light of $20 \mu \mathrm{mol}$ photons $\cdot \mathrm{m}^{-2} \cdot \mathrm{s}^{-1}$ (white LED lighting) at the culture surface with rotary agitation at $100 \mathrm{rpm}$; Infors HT 502,074 Minitron, Switzerland). The cells were grown under axenic conditions in Kuhl medium (Kuhl and Lorenzen 1964) prepared with deionised water, in 1 L Erlenmeyer flasks with a $20 \%$ working volume.

For the preservation experiments, the culture consisting of a mixture of motile cells and spore forms in its linear growth phase $\left(1.57 \mathrm{~g} \cdot \mathrm{L}^{-1}\right.$ biomass dry weight) was aliquoted into $50 \mathrm{~mL}$ closed Falcon tubes with minimal headspace. The tubes were stored in the dark at either $25^{\circ} \mathrm{C}$ (in a culture incubator) or $4{ }^{\circ} \mathrm{C}$ (in a cold room), without agitation for a period of 10 days (Online Resource 1). Two sets of experiments were conducted in triplicates: first, a preservation study was carried out in order to develop a rapid method for monitoring the viability of the algal biomass, directly through chlorophyll fluorescence measurement and 
indirectly through DNA quantification in the supernatant. Samples were taken, without replacement, at the beginning of the preservation period and after 1,2,5 and 10 days. The duration of study of 10 days was selected as a first approach to assess the changes in the quality of $C$. nivalis wet biomass stored at the above temperatures. The second experimental campaign evaluated the effect of several concentrations of acetic acid $(1,5,10,50$ and $100 \mathrm{mM})$ at $4{ }^{\circ} \mathrm{C}$ since this temperature exhibited enhanced preservation results during the first set of experiments compared to the obtained at 25 ${ }^{\circ} \mathrm{C}$. In this case, the $C$. nivalis culture was concentrated by centrifugation, and the resulting biomass was resuspended in growth medium containing acetic acid at the aforementioned concentrations. In this way, the same biomass concentration was used in the two studies $\left(1.5 \mathrm{~g} \cdot \mathrm{L}^{-1}\right.$ biomass concentration, stored in $50 \mathrm{~mL}$ tubes and in the darkness).

\section{Viability assays}

The viability of microalgal cells during storage was evaluated in two ways: first, by measuring the photosynthetic efficienc,y and second, by determining the presence of chlorophyll and DNA in the supernatant of the preserved suspension. The number of cells in the aliquots was also quantified, and the $\mathrm{pH}$ was monitored in order to define if there was any correlation between these parameters and the rest of the selected indicators.

\section{Photosynthetic efficiency measurement and chlorophyll concentration determination}

The maximum photosynthetic efficiency of PSII, also defined as the maximum quantum yield $\left(\mathrm{Qy}=\mathrm{F}_{\mathrm{v}} / \mathrm{F}_{\mathrm{m}}\right)$, was used as an indirect indicator of cell viability (Maxwell and Johnson 2000). Chlorophyll fluorescence $\left(F_{v} / F_{m}\right)$ was determined using the PAM technique by an AquaPEN AP-100 device (Photon System Instruments, Czech Republic) according to Bermejo et al. (2020). Aliquots ( $2 \mathrm{~mL})$ of stored $C$. nivalis were dark-adapted during $15 \mathrm{~min}\left(\mathrm{~F}_{0}\right)$ to oxidise the reaction centres of the photosystems and to obtain the level of basal fluorescence $\left(\mathrm{F}_{0}\right)$ before the application of a saturating pulse of actinic light which quickly saturates the reaction centre of the photosystems and induces the emission of maximum fluorescence $\left(\mathrm{F}_{\mathrm{m}}\right)$. The variable fluorescence of a darkadapted sample $\left(\mathrm{F}_{\mathrm{v}}\right)$ can be estimated from the difference between the above parameters $\left(\mathrm{F}_{\mathrm{m}}-\mathrm{F}_{0}\right)$. From these values, the maximum quantum yield was calculated according to the following equation from Cosgrove and Borowitzka (2011):

$\frac{F_{v}}{F_{m}}=\frac{\left(F_{m}-F_{0}\right)}{F_{m}}$
The chlorophyll concentration was determined after its extraction as described by the experimental protocol from Ben Amor-Ben Ayed et al. (2016) and subsequently its quantification according to Porras' equations (Porra 1990):

Chla $\left(m g \cdot L^{-1}\right)=\left(16.41 A_{664}-8.09 A_{650}\right) *$ dilutionfactor

$\operatorname{Chlb}\left(m g \cdot L^{-1}\right)=\left(30.82 A_{650}-12.57 A_{664}\right) *$ dilutionfactor

\section{Chlorophyll and DNA detection in the supernatant}

The presence of chlorophyll and DNA in the supernatant was measured as an index of metabolic damage in the microalgal biomass during its preservation. For chlorophyll detection, a sample of the stored suspension $(1 \mathrm{~mL})$ was centrifuged $(3000 \mathrm{xg} ; 10 \mathrm{~min}$.) and the spectrum of the supernatant was measured (380-730 nm, $50 \mathrm{~nm}$ steps) using a visible/UV spectrophotometer (UV-1800 spectrophotometer, Shimadzu, Switzerland). DNA was isolated and purified from the cells. The purification from the supernatant was accomplished by a DNA kit (SurePrep Soil DNA Isolation Kit, Fisher Scientific, USA). Prior to the isolation, the supernatant was passed through a sterile filter $(0.22-\mu \mathrm{m}$ pore size, Millex-GP, Millipore, USA) to ensure a cell-free sample. The purified DNA was quantified spectrophotometrically according to Eq. 4:

Abs $260 \times$ dilutionfactor $\times 50=\mu g D N A \cdot m L^{-1}$

The presence of DNA in the supernatant was validated through a polymerase chain reaction (PCR) and subsequent electrophoresis gel (Online Resource 2). A primer pair to partially amplified the $18 \mathrm{~S}$ rDNA sequence was used according to Lee et al. (2010) for its broad applicability to a wide variety of microalgae. The PCR was initiated with a denaturation step at $95^{\circ} \mathrm{C}$ for $5 \mathrm{~min}$. It was followed by 35 cycles with the following denaturation, annealing of primers and synthesis parameters: $95^{\circ} \mathrm{C}$ for $15 \mathrm{~s}, 56^{\circ} \mathrm{C}$ for $30 \mathrm{~s}$ and 72 ${ }^{\circ} \mathrm{C}$ for $45 \mathrm{~s}$. An extension step at $72{ }^{\circ} \mathrm{C}$ for $10 \mathrm{~min}$ was added at the end of the PCR. The limit of detection was determined by serial dilution of DNA extracted from $C$. nivalis cells in optimal conditions (Online Resource 3).

\section{Cell count and pH monitoring}

The number of cells and their size, at the beginning and at the end, of the preservation period was determined by a particle counting and characterisation system (Beckman Coulter Multisizer 4e counter, Beckman, USA). The preparation involved taking $100 \mu \mathrm{L}$ of the sample with the appropriate dilution (total volume $10 \mathrm{~mL}$ ) using an "electrolyte" saline solution in a special cuvette, previous filtration $(0.2 \mu \mathrm{m})$ and 
homogenisation to the Coulter determination. The $\mathrm{pH}$ of the suspension was measured at each time point.

\section{Evaluation of acetic acid efficiency as a preservative for microalgae biomass}

The impact of the addition of an additive on the microalgal biomass for its preservation was analysed by identifying the minimal inhibitory concentration of acetic acid, a commonly used preservative for food. An experimental campaign was carried out with $15-\mathrm{mL}$ vials in the absence of light and under the operating temperature of $4{ }^{\circ} \mathrm{C}$. The experiment was conducted in triplicates. Different concentrations of acetic acid were employed $(0,1,5,10,50$ and $100 \mathrm{mM})$. The inhibitory impact of this additive was evaluated through regular analyses of the photosynthetic activity of PSII, chlorophyll content, and DNA presence in the supernatant.

\section{Statistical analysis}

All the experiments were carried out in triplicates, and the data presented are the mean values of three independent replicates. The statistical differences between the treatments were evaluated using one-way analysis of variance (ANOVA). If ANOVA results were significant, comparisons among means were followed by a post hoc Tukey's multiple comparison tests, with a confidence level of 0.05 . The statistical analyses were performed using Minitab version 18 (Minitab® Statistical Software).

\section{Results and discussion}

\section{Evaluation of the photosynthetic efficiency during the preservation of $\mathrm{C}$. nivalis biomass}

A first study was performed to assess the correlation between chlorophyll fluorescence and chlorophyll concentration in $C$. nivalis cultures since this molecule has been described to present a positive relation with the photosynthetic activity (Chen et al. 2011). Chlorophyll is a crucial compound for the correct operation of the chloroplast, and thus, it can be considered a promising biomarker indicative of the status of a microalgal culture. Equation 5 was derived using chlorophyll fluorescence data (measured by the PAM technique) and chlorophyll concentration data (measured spectrophotometrically) through an experimental study based on serial dilutions of microalgal culture. A linear relationship was found between these parameters (cf. Fig. 1):

$\operatorname{Chl}\left(\mu \mathrm{g} \mathrm{mL} L^{-1}\right)=($ Chlfluoresc -0.3933$) / 0.0021$

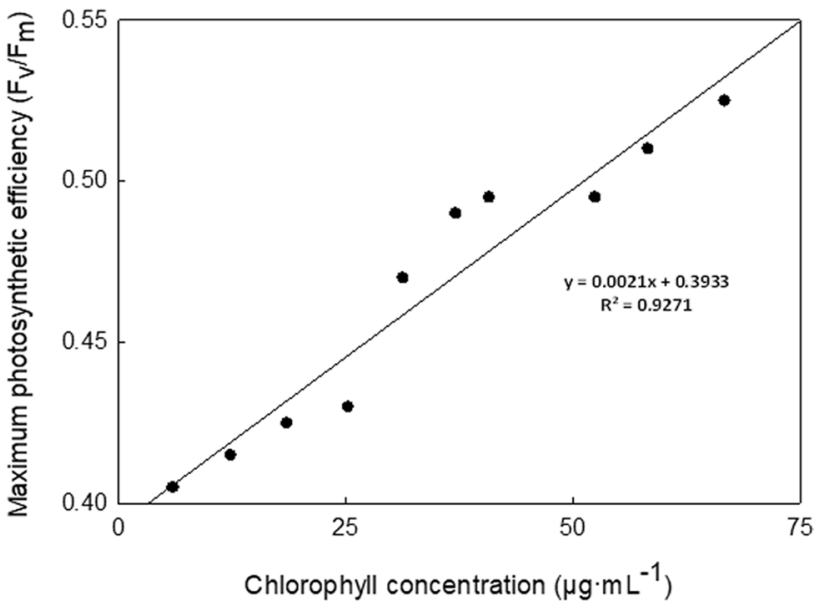

Fig. 1 Relationship between chlorophyll fluorescence $\left(\mathrm{F}_{\mathrm{v}} / \mathrm{F}_{\mathrm{m}}\right)$ and chlorophyll concentration $\left(\mu \mathrm{g} \cdot \mathrm{mL}^{-1}\right)$

$R^{2}=0.9271$

The good relationship obtained corroborates that the photosynthetic efficiency measured as chlorophyll fluorescence by the PAM technique is a useful tool for monitoring the quality of $C$. nivalis biomass especially during its storage and transport.

A real-time monitoring system is desired for the quality control of microalgae biomass and physiological status under storage conditions. Indeed, an accurate online measurement of biomass quality (physiological status of the microalgae) would allow efficient and precise monitoring, by feedback control, of the quality of the produced biomass. For instance, a real-time monitoring system can be integrated into the algae production and storage process in order to preserve an adequate quality of the biomass according to biomarkers.

During the preservation process, the microalgae biomass is susceptible to damage caused by inappropriate storage conditions (Heasman et al. 2001). The degradation of the quality of algal concentrated biomass during the preservation process impacts their shelf life, which depends on the algae species and storage conditions (Ponis et al. 2008). Thus, it is important to understand the shelf life of the microalgae culture (based on the biomarkers) during its preservation. Storage biomass is primarily impacted by two parameters: temperature (which should be as low as possible to slow down the biological metabolism of algae cells) and light (generally the biomass is maintained in the total absence of light). After harvesting, storing the microalgal biomass at low temperature has been reported as a promising method for maintaining cellular viability (Montaini et al. 1995; McCausland et al. 1999; Heasman et al. 2001; Harith et al. 2010; Castelló et al. 2017; Verspreet et al. 2020a). 
During this study, the objective was to evaluate the impact of two storage conditions on the cellular viability and chlorophyll content of $C$. nivalis: in darkness at $25^{\circ} \mathrm{C}$ (room temperature, which is the optimal temperature for the growth of the most microalgae species) and at $4{ }^{\circ} \mathrm{C}$ (conventional storage temperature applied in food storage). Although storage at low temperatures seems to be an adequate solution, this strategy is not ideal for industrial processes due to the increasing costs and necessary equipment associated with low temperature.

The effect of the storage conditions on $C$. nivalis biomass quality was studied through chlorophyll fluorescence measurements. The chlorophyll fluorescence value, expressed as the ratio $F_{v} / F_{m}$ (maximum PSII photosynthetic efficiency), was highly influenced by the temperature at which the cultures were stored (cf. Fig. 2). Alías et al. (2004) described the microalgal cellular stress in cultures in terms of chlorophyll fluorescence when the values of $\mathrm{F}_{\mathrm{v}} / \mathrm{F}_{\mathrm{m}}$ were below 0.4. In our study, the photosynthetic efficiency of $C$. nivalis stored in darkness at $25{ }^{\circ} \mathrm{C}$ after 10 days decreased by $85 \%$ when compared to the initial value, whereas in the case of cultures stored at $4{ }^{\circ} \mathrm{C}$, the drop in the photosynthetic activity was only $10 \%$. After 5 days of storage, cellular degradation and the decrease of photosynthetic activity were more noticeable for the biomass preserved at $25^{\circ} \mathrm{C}$. This degradation was much more progressive compared to storage at $4{ }^{\circ} \mathrm{C}$. This demonstrates the significant impact of temperature, especially at storage times longer than 5 days, which can be induced by oxygen limitation and/or by the activity of microbial contamination that can cause a reduction in

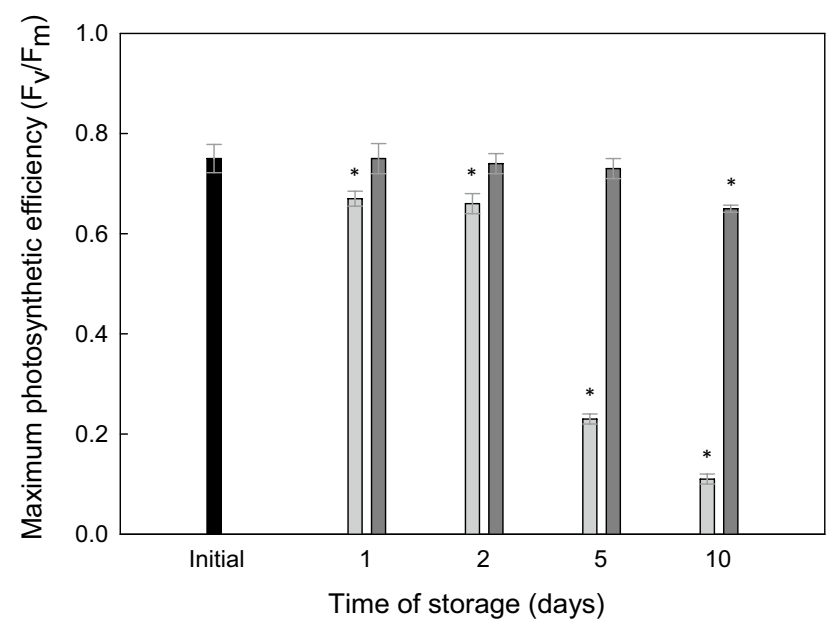

Fig. 2 Maximum photosynthetic efficiency measured as chlorophyll fluorescence $\left(\mathrm{F}_{\mathrm{v}} / \mathrm{F}_{\mathrm{m}}\right)$ of $C$. nivalis stored samples at the beginning of storage (- $)$ and after $1,2,5$ and 10 days of preservation at $25^{\circ} \mathrm{C}$ (_ _) and $4{ }^{\circ} \mathrm{C}$ (_ _ ). Error bars represent the standard deviation of replicates. $(*)$ indicates differences at the statistically significant level $\mathrm{p}<0.05$ (Tukey's pairwise test) within the different storage temperatures $\left(25^{\circ} \mathrm{C}\right.$ and $\left.4{ }^{\circ} \mathrm{C}\right)$ with respect to the initial value photosynthetic efficiency. Photosynthesis is well-known to be regulated by natural factors such as temperature, as it can cause an impact on the structure and activity of microalgae proteins, including those that are part of the PSII reaction centres (Béchet et al. 2017). It has been also described that low temperatures slow metabolic processes such as oxidative denaturation of essential vitamins, autolysis and microbial degradation while maintaining the viability of the cells (Heasman et al. 2001), which matches the results obtained for the cultures stored at $4{ }^{\circ} \mathrm{C}$. On the other hand, the observations from the cultures at $25{ }^{\circ} \mathrm{C}$ could have been influenced by the fact that they were stored in totally closed tubes with minimal headspace, since it has been suggested that, either oxygen limitation or the accumulation of a gaseous metabolite, or both, can cause photosynthetic efficiency reduction (Montaini et al. 1995).

\section{Evaluation of the chlorophyll and DNA content in the supernatant during biomass preservation}

The conservation of cell membrane integrity, cellular content and its chemical and biological integrity are considered an important prerequisite to extend the quality of the microalgal cells (Heasman et al. 2001). In the present work, the presence of chlorophyll and DNA in the supernatant was a sign of cellular degradation. Chlorophyll interacts with light and therefore has a characteristic visible/UV spectrum with peaks around $430 \mathrm{~nm}$ and $680 \mathrm{~nm}$, which is a helpful property to identify any pigment and its degradation products. It has been described that chlorophyll- $a$, and most of its breakdown derivatives such as pheophytin, has similar spectra (Hendry et al. 1987). Therefore, the viability of $C$. nivalis cultures during preservation was evaluated at $430 \mathrm{~nm}$ and $680 \mathrm{~nm}$. An increase was detected in the absorbance measured in the supernatant of samples after 10 days of preservation as compared to the initial value, being 3.6 and 3.9 times more pronounced in those cells stored at 25 ${ }^{\circ} \mathrm{C}$ compared to the absorbance values obtained at $4{ }^{\circ} \mathrm{C}$ (cf. Fig. 3b). This is most likely due to the release of chlorophyll degradation material into the suspension media as a consequence of cell death. The production of catabolites derived from the degradation of the chlorophyll molecule has been widely reported in higher plants; however, few studies document the excretion to the medium of these compounds by microalgae. On this matter, Grabski et al. (2016) observed, through an increase in the absorbance, that Desmodesmus subspicatus cells released products of chlorophyll degradation when the alga grew under stress conditions, which is in agreement with the behaviour detected in $C$. nivalis when stored at $25^{\circ} \mathrm{C}$.

Regarding the detection of DNA, a decrease in the average amount of DNA measured spectrophotometrically in C. nivalis cells, while finding an increase in the supernatant, 

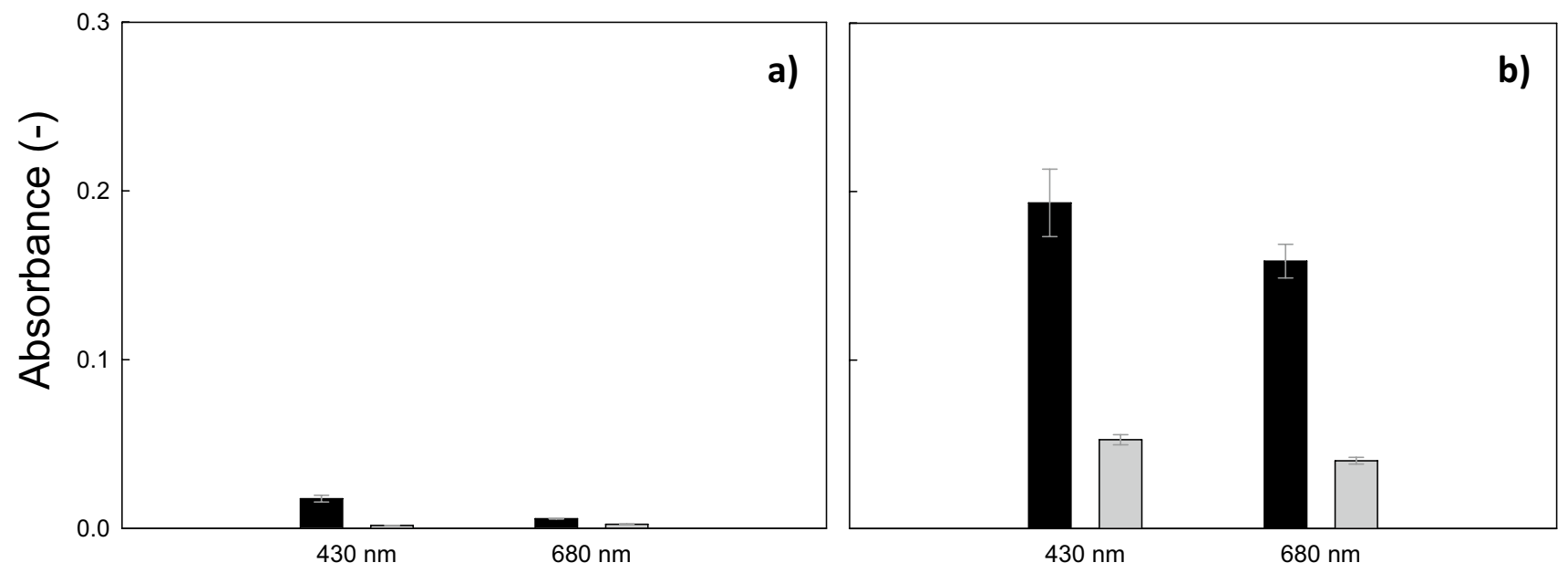

Fig. 3 Chlorophyll absorbance measured in C. nivalis supernatant from samples stored at $25{ }^{\circ} \mathrm{C}\left({ }_{-}\right)$and $4{ }^{\circ} \mathrm{C}\left({ }_{-}\right)$, after a 5 days and b 10 days of preservation. Values show the change in absorbance

was observed in samples at both storage temperatures, 25 ${ }^{\circ} \mathrm{C}$ and $4{ }^{\circ} \mathrm{C}$ (cf. Fig. 4a). Whereas the DNA content in $C$. nivalis biomass decreased $55 \%$ after 10 days at $25^{\circ} \mathrm{C}$, it only decreased by $33 \%$ in cultures preserved at $4{ }^{\circ} \mathrm{C}$. DNA measured by absorbance from cells and supernatant fractions of C. nivalis was validated by agarose gel electrophoresis (cf. Fig. 4b). An increase in free microalgal DNA in the supernatant has been associated with a cell viability reduction in bacteria populations (Treimo et al. 2006). In our study, this was corroborated by the high correlation between the photosynthetic efficiency and the amount of DNA released into the medium (cf. Fig. 5a), demonstrating that as the amount of DNA increased in the supernatant, the photosynthetic measured in the supernatant of the culture based on the initial absorbance value of the storage period. Error bars represent the standard deviation of replicates

activity and viability of the stored cultures decreased. This is an interesting finding since no research has been carried out so far with microalgae, correlated the presence of DNA in the supernatant with the viability of the culture. Thus, monitoring DNA in microalgae suspensions can be proposed as a qualitative indicator of the status of the stored biomass.

\section{Influence of storage conditions in the biomass concentration and $\mathrm{pH}$}

Biomass concentration (cells $\cdot \mathrm{mL}^{-1}$ ), as measured by Coulter particle counter, was quantified at different points during the preservation process. Even though an important

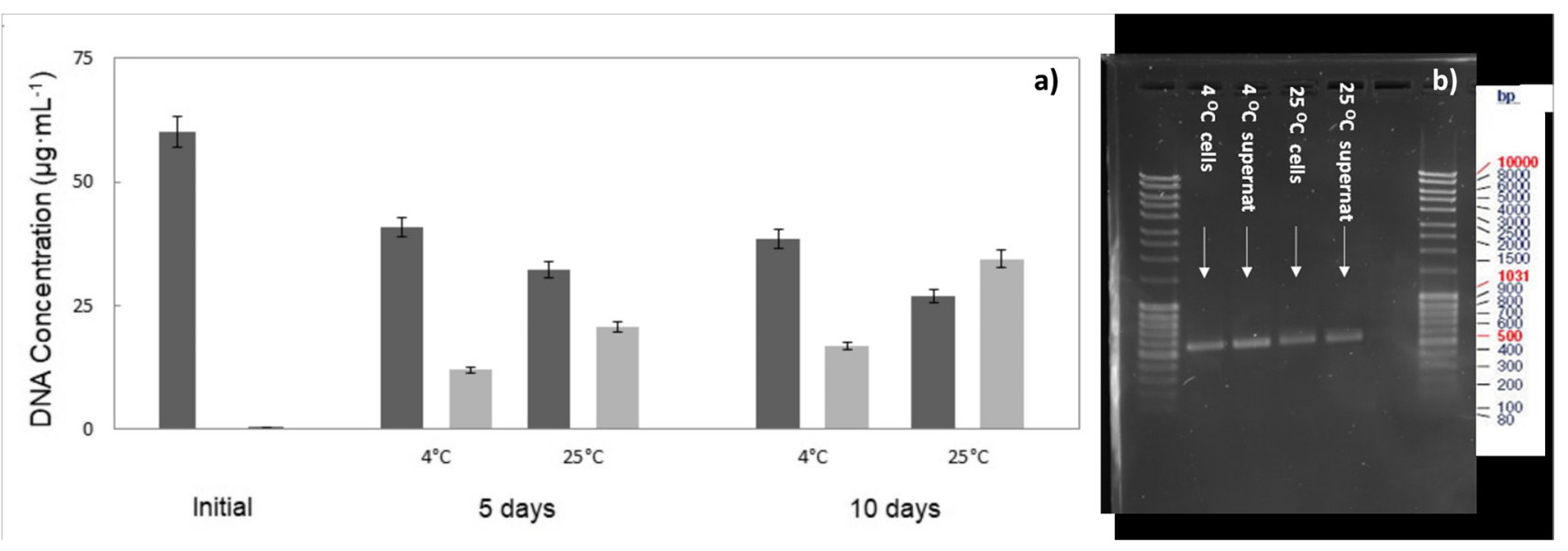

Fig. 4 a DNA concentration measured in cells (- - ) and in the supernatant (_ $\_$) of stored C. nivalis samples at $4{ }^{\circ} \mathrm{C}$ and $25^{\circ} \mathrm{C}$. Error bars represent the standard deviation of replicates. b Purified DNA on agarose gel from the supernatant and cells fractions of $C$. nivalis stored at $4{ }^{\circ} \mathrm{C}$ and $25{ }^{\circ} \mathrm{C}$ after 10 days. The last lane is a negative control (no DNA template). The DNA strands were separated for $1 \mathrm{~h}(100 \mathrm{~V})$ on agarose gel (1\%). A DNA ladder (Thermo Scientific MassRuler) ranging from 80 to $10,000 \mathrm{bp}$ is shown 
a)

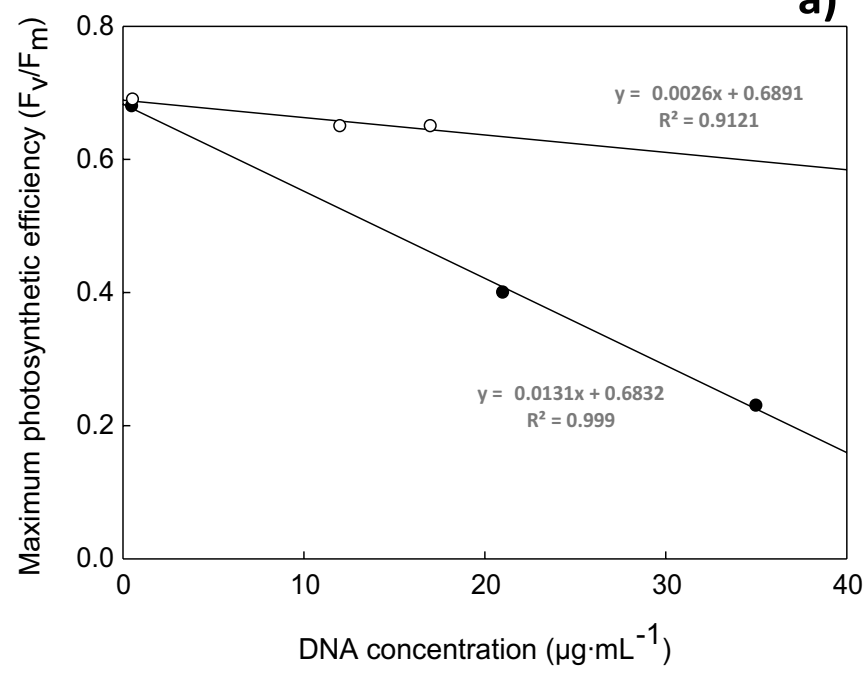

Fig. 5 a Relationship between chlorophyll fluorescence $\left(\mathrm{F}_{v} / \mathrm{F}_{\mathrm{m}}\right)$ of the suspension and the free DNA concentration $\left(\mu \mathrm{g} \cdot \mathrm{mL}^{-1}\right)$ in the supernatant of $C$. nivalis samples stored at $25^{\circ} \mathrm{C}(\mathbf{O})$ and $4{ }^{\circ} \mathrm{C}(\bigcirc)$. b Rela-

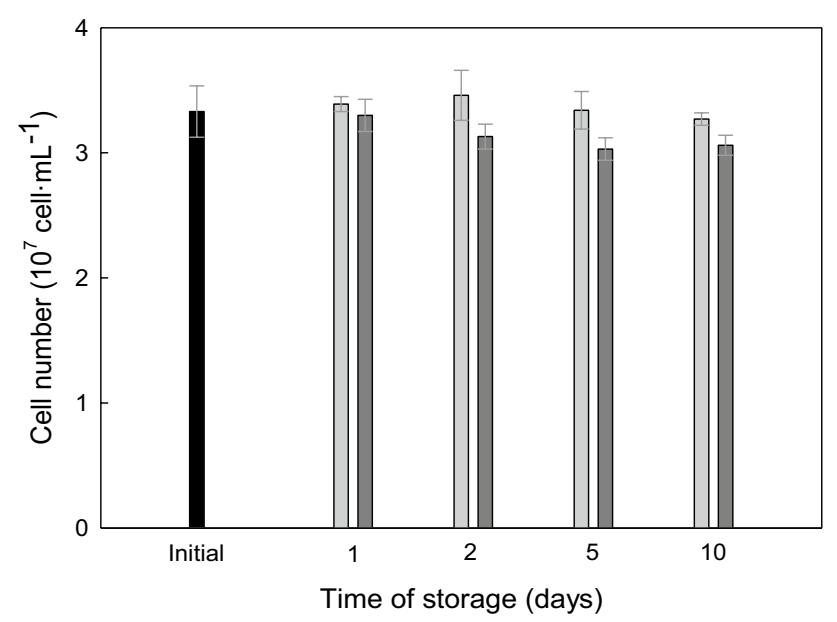

Fig. 6 Variation in the cell concentration of $C$. nivalis culture during the preservation period at different temperatures. Samples were taken the beginning (-) and then at 1,2,5 and 10 days of storage at 25 ${ }^{\circ} \mathrm{C}$ (_ _ $_{\text {) }}$ and $4{ }^{\circ} \mathrm{C}$ (_ $\left._{-}\right)$. Error bars represent the standard deviation of replicates. There were no statistically significant differences along the time between storage temperatures with respect to the initial value

decrease in the photosynthetic activity occurred during storage, especially at $25^{\circ} \mathrm{C}$, no significant differences were detected in the number of cells (cf. Fig. 6). A very slight increase in the concentration of the algal suspension was highlighted up to 2 days, and then there was a clear stabilisation through 10 days of storage. This slight growth can be explained by a still active cellular metabolism, even in the dark, that allowed some cell multiplication in the

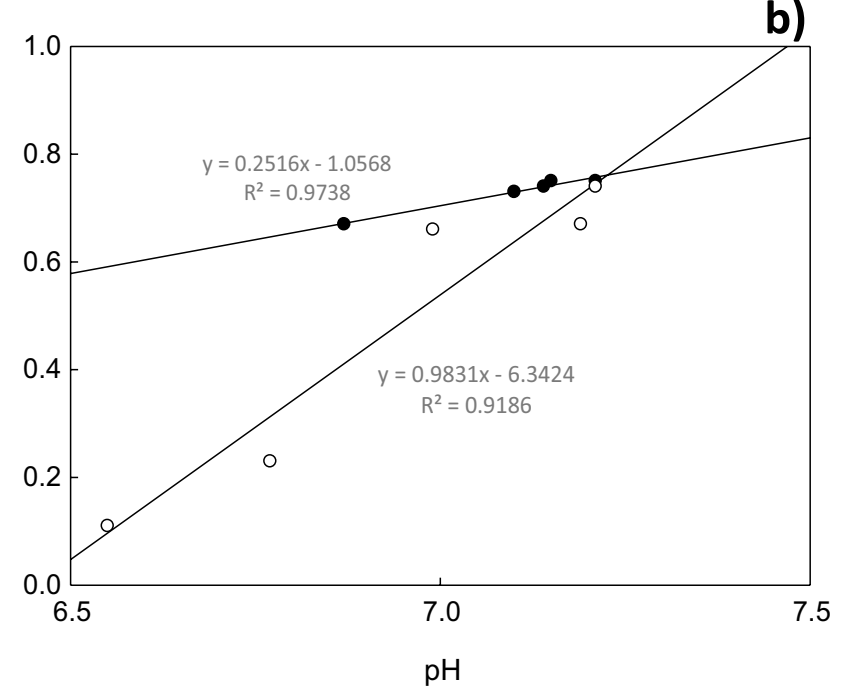

tionship between chlorophyll fluorescence $\left(\mathrm{F}_{\mathrm{v}} / \mathrm{F}_{\mathrm{m}}\right)$ and $\mathrm{pH}$ of $C$. nivalis suspensions stored at $4{ }^{\circ} \mathrm{C}(\mathbf{O})$ and $25^{\circ} \mathrm{C}(\mathrm{O})$

presence of nutrients and carbon sources at an optimal temperature of $25^{\circ} \mathrm{C}$. Under storage conditions at $4{ }^{\circ} \mathrm{C}$, a progressive decrease in cell concentration was observed, which highlights the impact of low temperatures on the reduction of the metabolic processes of the algal biomass. In conclusion, these results show that cellular quantification of biomass cannot be exploited as a direct or indirect indicator or biomarker of the quality of the stored biomass. This fact highlights the need to use biomarkers, such as chlorophyll fluorescence, which disclose the physiological status of the microalgae cultures before detecting changes in their cellular content. Chlorophyll fluorescence reflects the photochemical processes yield in the photosynthetic apparatus, especially in the PSII, and subsequently its biomass production (Masojídek et al. 2011).

The $\mathrm{pH}$ is one of the major parameters used as an indicator during the mass culture of microalgae. The $\mathrm{pH}$ of $C$. nivalis cultures was also monitored during the preservation period. A proportionality with good accuracy was confirmed between photosynthetic efficiency and $\mathrm{pH}$ (cf. Figure $5 \mathrm{~b}$ ). A decreasing trend in the $\mathrm{pH}$ of the stored cultures was directly related to a reduction in the photosynthetic process. It can be also related to the respiration metabolism of the microalgae cells in a dark storage condition. Indeed, during the dark phase, microalgae release carbon dioxide, which induces acidification of the medium, according to the cellular activity of the stored microalgae biomass. The integrity of the microalgae biomass during the 10 days of storage is shown in Online Resource 4. 


\section{Effect of acetic acid addition on the preservation of $\mathrm{C}$. nivalis cultures stored at $4^{\circ} \mathrm{C}$}

The effect of acetic acid addition at different concentrations $(0,1,5,10,50$ and $100 \mathrm{mM})$ was studied in cultures stored at $4{ }^{\circ} \mathrm{C}$ since this temperature generated better results for C. nivalis preservation. This organic acid has been reported to minimise antimicrobial activity for food preservation (Belitz et al. 2009; Wali and Abel 2019). The toxic effect of acetic acid at concentrations above $5 \mathrm{mM}$ is highlighted in Fig. 7a. Indeed, at these concentrations, acetic acid negatively altered the photosynthetic activity of the biomass from the very beginning of the storage process. This can be understood as the action of a more acidic $\mathrm{pH}$ which accelerates the cellular deterioration of the algal biomass. On the other hand, the photosynthetic activity of the culture remained above 0.6 at the concentration of 1 to $5 \mathrm{mM}$ of acetic acid for the whole storage period, indicating the suitability of these concentrations for the preservation of the algal biomass. In addition, at the lowest acetic acid concentration $(1 \mathrm{mM})$, the photosynthetic activity of the biomass did not show significant differences with that observed in the absence of the preservative during the whole period (Fig. 7a).

The efficiency of acetic acid for the preservation of $C$. nivalis is confirmed when looking at the DNA and chlorophyll concentration in the supernatant (Fig. $7 \mathrm{~b}$ and c). At an acetic acid concentration up to $5 \mathrm{mM}$, the chlorophyll content of the supernatant remains constant during the storage, and there was much lower DNA released into the supernatant than observed at higher concentrations. The best preservation was observed with acetic acid addition at a concentration of $1 \mathrm{mM}$. This can be explained by the antimicrobial action of the acetic acid, which has already been proven during the storage of the microalga Nannochloropsis gaditana (Verspreet et al. 2020a). Future research on the bacterial load (heterotrophic and Vibrio-type) should be done to validate the results obtained for $C$. nivalis when adding a concentration of $1 \mathrm{mM}$ of acetic acid.

\section{Conclusions}

In the present study, good correlations between chlorophyll fluorescence and the amount of DNA and chlorophyll detected in the extracellular environment were obtained. These results demonstrated that the PAM technique, using a measurement of chlorophyll fluorescence, offers a good option for a mobile, rapid and easy-to-use determination of the viability of microalgae cultures during storage. This is of great importance since for any quality control system, it is key to have a marker that correlates well with the quality parameter of interest and to be able to monitor that marker over time in order to ensure the reproducibility and
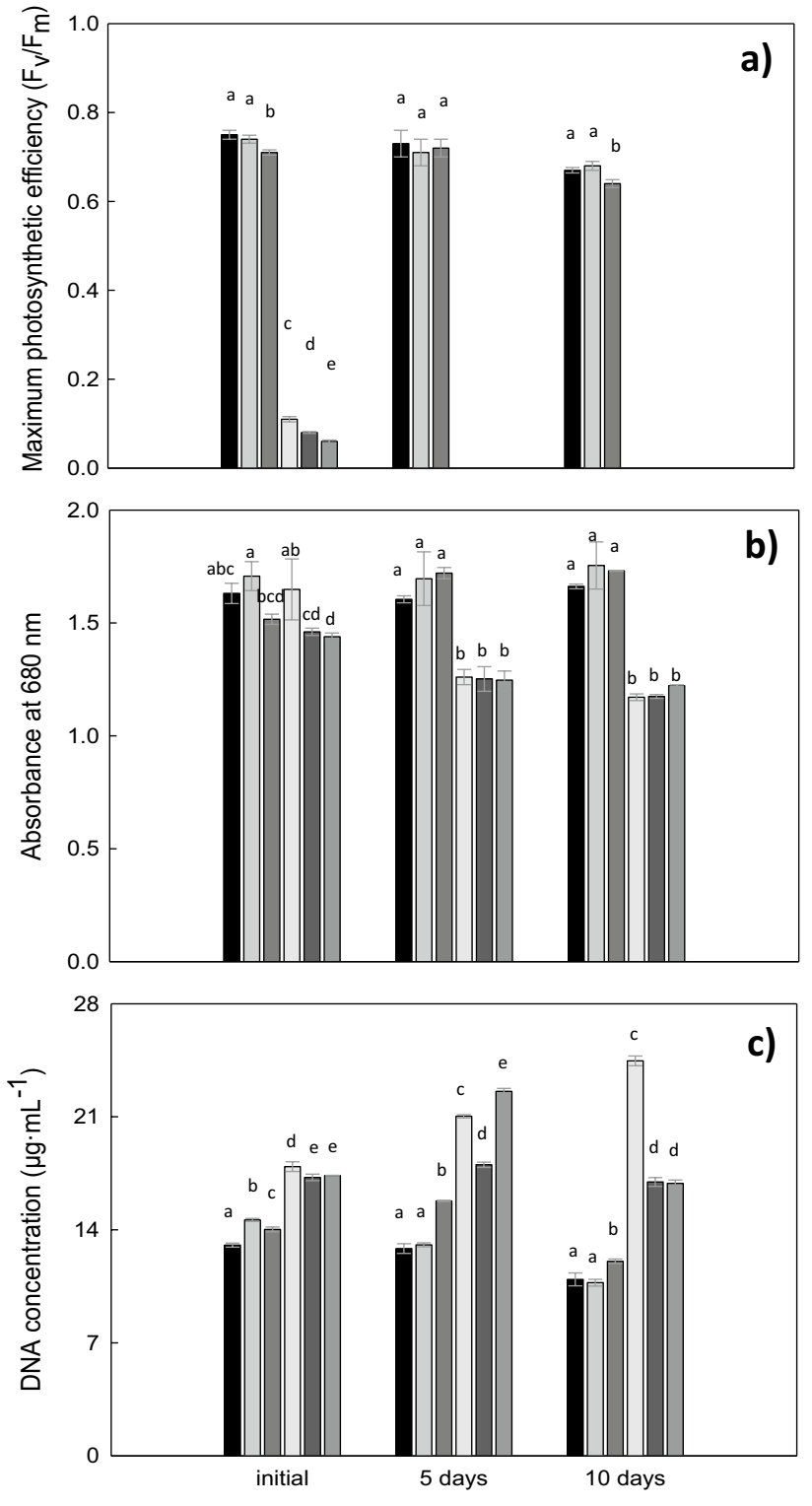

Fig. 7 a Photosynthetic activity, b absorbance at $680 \mathrm{~nm}$ and c DNA concentration in the supernatant, measured in $C$. nivalis samples stored at $4{ }^{\circ} \mathrm{C}$ at the initial time, and after 5 and 10 days of preservation, with different acetic acid concentrations; from left to right,

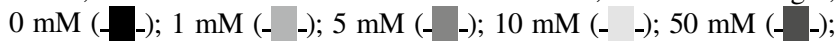
$100 \mathrm{mM}$ ( - $)$. Error bars represent the standard deviation of replicates. The different letters indicate differences at the significance level of $\mathrm{p}<0.05$ (Tukey's test)

constancy of the product. In the same way, the monitoring of DNA content can be used as a qualitative indicator of the viability and health of a microalgal stored biomass. According to these overall results, the lowest temperature $\left(4{ }^{\circ} \mathrm{C}\right)$ was the most suitable to maintain the quality of $C$. nivalis cells at least during 10 days of storage. Under these conditions, microalgal samples maintained maximum cellular integrity and intracellular biological composition, based on the monitoring of the photosynthetic activity of PSII and 
the amount of chlorophyll and DNA released in the supernatant. However, knowing the economic and energy costs required to maintain biomass preservation at this low temperature, there is a need to evaluate the storage of $C$. nivalis at higher temperatures, around $8{ }^{\circ} \mathrm{C}$. The impact of acetic acid, a preservative for the food industry, has been studied at $4{ }^{\circ} \mathrm{C}$. This study highlighted the preservative action of the addition of acetic acid, at a concentration of $1 \mathrm{mM}$, allowing the stabilisation of the cellular integrity of the biomass in terms of PSII photosynthetic activity and the content of DNA released in the supernatant of the algal suspension. This study proposes that biomass from $C$. nivalis cultures should be stored at a temperature of $4{ }^{\circ} \mathrm{C}$ and with the addition of $1 \mathrm{mM}$ acetic acid. These storage conditions will minimise the biomass degradation for up to 10 days of storage.

Acknowledgements This work has been supported financially by the European Union under the Interreg NWE Programme (IDEA Project, www.nweurope.eu; contract number, NWE 669).

Data availability The datasets generated during and/or analysed during the current study are available from the corresponding author on reasonable request.

\section{Declarations}

Conflict of interest The authors declare no competing interests.

Open Access This article is licensed under a Creative Commons Attribution 4.0 International License, which permits use, sharing, adaptation, distribution and reproduction in any medium or format, as long as you give appropriate credit to the original author(s) and the source, provide a link to the Creative Commons licence, and indicate if changes were made. The images or other third party material in this article are included in the article's Creative Commons licence, unless indicated otherwise in a credit line to the material. If material is not included in the article's Creative Commons licence and your intended use is not permitted by statutory regulation or exceeds the permitted use, you will need to obtain permission directly from the copyright holder. To view a copy of this licence, visit http://creativecommons.org/licenses/by/4.0/.

\section{References}

Alías CB, García-Malea López MC, Acién-Fernández FG, FernándezSevilla JM, García-Sánchez JL, Molina-Grima E (2004) Influence of power supply in the feasibility of Phaeodactylum tricornutum cultures. Biotechnol Bioeng 87:723-733

Babic J (2013) Acetic acid in the food industry. In: Acetic Acids, Chemical Properties, Production and Applications. Nova Publishers, NY 163-176

Baker NR (2008) Chlorophyll fluorescence: a probe of photosynthesis in vivo. Annu Rev Plant Biol 59:89-113

Béchet Q, Laviale M, Arsapin N, Bonnefond H, Bernard O (2017) Modeling the impact of high temperatures on microalgal viability and photosynthetic activity. Biotechnol Biofuels 10:136

Belitz HD, Grosch W, Schiberle P (2009) Food chemistry, 3rd ed. Springer, Berlin
Ben Amor-Ben Ayed H, Taidi B, Ayadi H, Pareau D, Stambouli M (2016) Magnesium uptake by the green microalga Chlorella vulgaris in batch cultures. J Microbiol Biotechnol 26(3):503-510

Bermejo E, Filali R, Behnam T (2021) Microalgae culture quality indicators: a review. Crit Rev Biotechno 41:457-473

Bermejo E, Muñoz A, Ramos-Merchante A, Vílchez C, Garbayo I, Cuaresma M (2020) Medium optimisation as a first step towards the feasible production of biopolymers with Botryococcus braunii. J Appl Phycol 32:3667-3678

Castelló ML, Pariente G, Andrés A, Ortolá MD (2017) Evaluation of strategies for preservation of microalgae Chlorella. J Food Process Preserv 42:e13518

Chacón-Lee TL, González-Mariño GE (2010) Microalgae for "healthy" foods - possibilities and challenges. Comp Rev Food Sci Food Safety 9:655-675

Chen X, Goh QY, Tan W, Hossain I, Chen WN, Lau R (2011) Lumostatic strategy for microalgae cultivation utilizing image analysis and chlorophyll $a$ content as design parameters. Bioresour Technol 102:6005-6012

Cosgrove J, Borowitzka MA (2011) Chlorophyll fluorescence terminology: an introduction. In: Suggett DJ, Prášil O, Borowitzka MA (eds) Chlorophyll- $a$ fluorescence in aquatic sciences. Springer, Dordrecht, pp 1-17

Dan SD, Mihaiu M, Reget O, Oltean D, Tabaran A (2017) Pathogens contamination level reduction on beef using organic acids decontamination methods. Bull UASVM Vet Med 74:212-217

Grabski K, Baranowski N, Skórko-Glonek J, Tukaj Z (2016) Chlorophyll catabolites in conditioned media of green microalga Desmodesmus subspicatus. J Appl Phycol 28:889-896

Harith ZT, Yusoff FM, Shariff M, Ariff AB (2010) Effect of different separation techniques and storage temperatures on the viability of marine microalgae, Chaetoceros calcitrans, during storage. Biotechnology 9:387-391

Heasman MP, Sushames TM, Diemar JA, O'Connor WA, Foulkes LA (2001) Production of microalgal concentrates for aquaculture part 2: Development and evaluation of harvesting, preservation, storage and feeding technology. NSW Fishereries Final Report https://www.dpi.nsw.gov.au/_data/assets/pdf_file/0004/134581/ Output-34.pdf

Hendry GAF, Houghton JD, Brown SB (1987) The degradation of chlorophyll- $a$ biological enigma. New Phytol 107:255-302

Koca N, Karadeniz F, Burdurlu HS (2005) Effect of pH on chlorophyll degradation and colour loss in blanched green peas. Food Chem 100:609-615

Kromkamp JC, Dijkman NA, Peene J, Simis SGH, Gons HJ (2008) Estimating phytoplankton primary production in Lake IJsselmeer (the Netherlands) using variable fluorescence (PAM-FRRF) and C-uptake techniques. Eur J Phycol 43:327-344

Kuhl A, Lorenzen H (1964) Handling and culturing of Chlorella. In: Prescott DM (ed) Methods in Cell Physiology. Academic Press, New York, pp 152-187

Lee S, Oak JH, Chung IK, Lee JA (2010) Effective molecular examination of eukaryotic plankton species diversity in environmental seawater using environmental PCR, PCR-RFLP, and sequencing. J Appl Phycol 22:699-707

McCausland MA, Brown MR, Barrett SM, Diemar JA, Haesman MP (1999) Evaluation of live microalgae and microbial pastes as supplementary food for juvenile Pacific oyster (Crassostrea gigas). Aquaculture 174:323-342

Masojídek J, Torzillo G, Koblízek M, Kopecký J, Bernardini P, Sacchi A, Komenda J (1999) Photoadaptation of two members of the Chlorophyta (Scenedesmus and Chlorella) in laboratory and outdoor cultures: changes in chlorophyll fluorescence quenching and the xanthophyll cycle. Planta 209:126-135

Masojídek J, Vonshak A, Torzillo G (2011) Chlorophyll fluorescence applications in microalgal mass cultures. In: Suggett D, Prášil 
O, Borowitzka M (eds) Chlorophyll $a$ Fluorescence in Aquatic Sciences: Methods and Applications. Springer, Dordrecht, pp 277-292

Masojídek J, Koblížek M, Torzillo G (2013) Photosynthesis in microalgae. In: Richmond A, Hu Q (eds) Handbook of microalgal culture: applied phycology and biotechnology. Wiley Blackwell, Oxford, pp 20-39

Maxwell K, Johnson GN (2000) Chlorophyll fluorescence-a practical guide. J Exp Bot 51(345):659-668

Montaini E, Zittelli C, Tredici MR, Molina Grima E, Fernández Sevilla JM, Sinchez Perez JA (1995) Long-term preservation of Tetraselmis suecica: influence of storage on viability and fatty acid profile. Aquaculture 134:81-90

Oxborough K, Hanlon ARM, Underwood GJC, Baker NR (2000) In vivo estimation of the photosystem II photochemical efficiency of individual microphytobenthic cells using high-resolution imaging of chlorophyll a fluorescence. Limnol Oceanogr 45:1420-1425

Paniagua-Michel J, Olmos-Soto J (2016) Modern approaches into biochemical and molecular biomarkers: key roles in environmental biotechnology. J Biotechnol Biomater 6:1

Ponis E, Parisi G, Chini-Zittelli G, Lavista F, Robert R, Tredici MR (2008) Pavlova lutheri: production, preservation and use as food for Crassostrea gigas larvae. Aquaculture 282:97-103

Porra R (1990) The assay of chlorophylls $a$ and $b$ converted to their respective magnesium rhodochlorin derivatives by extraction from recalcitrant algal cells with aqueous alkaline methanol: prevention of allomerization with reductants. Biochim Biophys Acta Bioenerg 1015:493-502

Segovia M, Haramaty L, Berges JA, Falkowski PG (2003) Cell death in the unicellular chlorophyte Dunaliella tertiolecta. A hypothesis on the evolution of apoptosis in higher plants. Plant Physiol 132:99-105

Treimo J, Vegarud G, Langsrud T, Rudi K (2006) Use of DNA quantification to measure growth and autolysis of Lactococcus and Propionibacterium spp. in mixed populations. Appl Environ Microbiol 72:6174-6182

Torcillo G, Accolla P, Pinzani E, Masojidek J (1996) In situ monitoring of chlorophyll fluorescence to assess the synergistic effect of low temperature and high irradiance stresses in Spirulina cultures grown outdoors in photobioreactors. J Appl Phycol 8:4-5

Torzillo G, Bernardini P, Masojidek J (1998) On-line monitoring of chlorophyll fluorescence to assess the extent of photoinhibition induced by high oxygen concentration and low temperature and its effect on the productivity of outdoor cultures of Spirulina platensis (cyanobacteria). J Phycol 34:504-510

Veloso AC, Ferreira EC (2017) Online analysis for industrial bioprocesses: Broth Analysis. In: Larriche C, Sanroman MA, Du G, Pandey A (eds) Current Developments in Biotechnology and Bioengineering: Bioprocesses, Bioreactors and Controls. Elsevier, Amsterdam, pp 679-704

Venkateswaran K, Hattori N, La Duc MT, Kern R (2003) ATP as a biomarker of viable microorganisms in clean-room facilities. J Microbiol Meth 52(3):367-377

Verspreet J, Kreps S, Bastiaens L (2020a) Evaluation of microbial load, formation of odorous metabolites and lipid stability during wet preservation of Nannochloropsis gaditana concentrates. Appl Sci 10:3419

Verspreet J, Soetemans L, Bastiaens L (2020b) Searching for appropriate storage conditions for short-term wet preservation of Porphyridium purpureum. Appl Sci 10:8315

Vonshak A, Torzillo G, Tomaseli L (1994) Use of chlorophyll fluorescence to estimate the effect of photoinhibition in outdoor cultures of Spirulina platensis. J Appl Phycol 6:31-34

Wali MK, Abed MM (2019) Antibacterial activity of acetic acid against different types of bacteria causes food spoilage. J Food Technol Preserv 3(1).

Yordanova ZP, Woltering EJ, Kapchina-Toteva VM, Iakimova ET (2013) Mastoparan-induced programmed cell death in the unicellular alga Chlamydomonas reinhardtii. Ann Bot 111:191-205

Zuppini A, Andreoli C, Baldan B (2007) Heat stress: an inducer of programmed cell death in Chlorella saccharophila. Plant Cell Physiol 48:1000-1009

Publisher's note Springer Nature remains neutral with regard to jurisdictional claims in published maps and institutional affiliations. 